\title{
CFD Simulation and Experimental Study of Key Design Parameters of Solar Thermal Collectors
}

\author{
J. Allan ${ }^{\text {a, } 1,2}$, Z. Dehouche ${ }^{1}$, S. Stankovic ${ }^{2}$ and A. Harries ${ }^{3}$ \\ ${ }^{I}$ School of Engineering and Design, Brunel University, London, UB8 3PH, United Kingdom \\ ${ }^{2}$ ChapmanBDSP, Saffron House, 6-10 Kirby Street, London, EC1N 8EQ \\ ${ }^{3}$ Savills, 33 Margaret Street, London, WIG OJD
}

\section{Abstract}

Numerical simulation enables the optimization of a solar collector without the expense of building prototypes. This study details an approach using Computational Fluid Dynamics (CFD) to simulate the performance of a solar thermal collector. Inputs to the simulation include; heat loss coefficient, irradiance and ambient temperature. A simulated thermal efficiency was validated using experimental results by comparing the calculated heat removal factor. The validated methodology was then applied to5 different inlet configurations of a header-riser collector. The most efficient designs had uniform flow through the risers. The worst performing configurations had low flow rates in the risers that led to high surface temperatures and poor thermal efficiency. The calculated heat removal factor differed by between $4.2 \%$ for the serpentine model and $12.1 \%$ for the header riser. The discrepancies were attributed to differences in thermal contact between plate and tubes in the simulated and actual design. 


\section{Nomenclature}

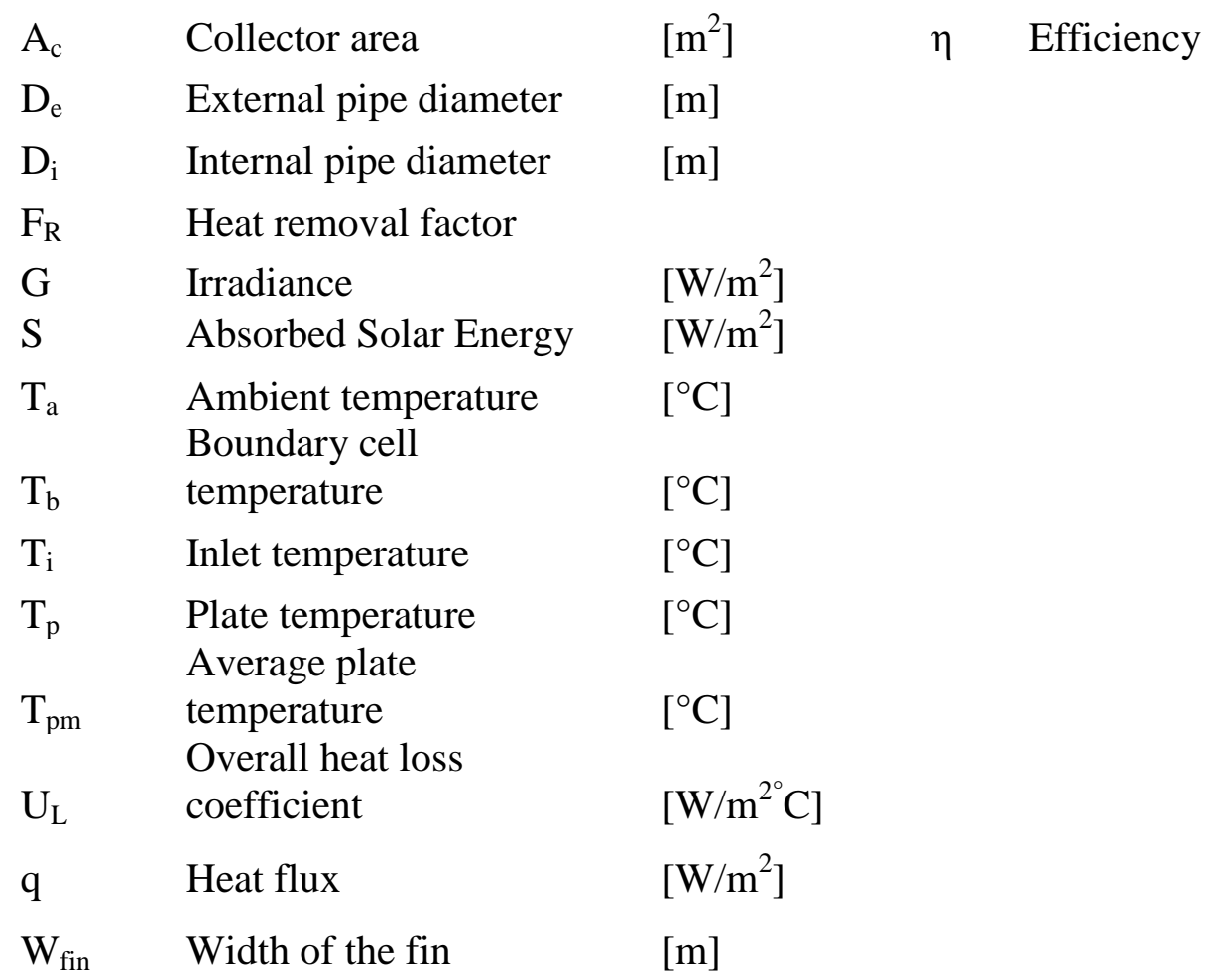




\section{Introduction}

The useful energy output of a flat plate solar collector can be described using an energy balance equation (1) [4]:

$$
Q_{u}=A_{c}\left[S-U_{L}\left(T_{p m}-T_{a}\right)\right]
$$

Where $A_{c}$ is the collector area, $S$ is the absorbed solar energy, $U_{L}$ is the overall heat loss coefficient, $T_{p m}$ is the average plate temperature and $T_{a}$ is the ambient temperature.

Whillier and Bliss developed an empirical model to express the performance of a solar collector in terms of its inlet temperature using the heat removal factor, $F_{R}$, which is the ratio of the actual to the maximum possible energy gain. The heat removal factor is a function of the design of the collector. The expression for the heat removal factor calculation is given in [4]. The heat removal factor can then be used to determine the useful energy gain from a solar collector using (2).

$$
Q_{u}=A_{c} F_{R}\left[\left(S-U_{L}\left(T_{i}-T_{a}\right)\right)\right]
$$

Computational Fluid Dynamics (CFD) is a finite numerical method to solve fluid flow and heat transfer equations. The post-processing of CFD results enables visualization which is useful for parametric optimization of collector design. A comprehensive review of numerical methods to model solar collectors is given by Tagliafico et al. [16]

\section{CFD Studies of Solar Technologies}

Fan et al. used CFD to investigate flow distribution in an exceptionally large solar collector consisting of horizontally inclined absorber strips [6]. The model was validated against experimental results. The temperature on the backside of the absorber tubes was measured experimentally using thermocouples. These temperatures were adjusted to convert the wall temperatures into fluid temperatures and a simplified CFD model was created using heat flux [W/m] (3).

$$
\text { heat flux }=W_{f i n} \eta_{0} G
$$


Where $W_{f i n}$ is the width of the fin (m) $\eta_{0}$ is the zero-loss efficiency and $G$ is the solar irradiance. The only losses that were taken into consideration in the CFD model were convective losses and the heat loss coefficient in the model was adjusted so that collector efficiency is equal to the experimentally measured efficiency. A high-density mesh with 1.4 million mesh cells was used. Using CFD, Fan investigated:

- Flow distribution under isothermal flow using a non-uniformity parameter

- Inlet flow rate and temperature

- Collector tilt angle

- Properties of the solar fluid

Fan et al. characterised isothermal fluid flow through each tube as a percentage of total flow to determine the flow uniformity. Fan found that, in the 16 pipes modeled, flow rate is decreased from the top to the bottom and worsens when the inlet flow is increased. Low flow rates and steep inclinations led to increased buoyancy effects and Fan highlighted a risk of boiling in the tubes with stagnant flow. Through this analysis it was recommended to use gradual inclinations and fast flow rates to achieve flow uniformity.

Another CFD study was carried out by Selmi [14]. The CFD problem was multi-domain and included physical models for radiative and convective heat transfer between the collector components. The collector geometry modelled by Selmi consisted of a single pipe fixed to an aluminium absorber inside a wooden box with a glazed cover. Both passive and active flow operating conditions were modeled and measured. Selmi measured: water inlet temperature, water outlet temperature, absorber plate temperature, pipe temperature, ambient temperature, solar irradiation and water flow rate. A transient simulation was carried out over a day with changing values of solar irradiation. When the experimental results were compared with the results from the simulation, there was good agreement; however, the temperature difference between inlet and outlet did not reduce when inlet temperature increased, this indicates that the model did not consider the heat loss coefficient of the model appropriately.

The flow distribution in a solar air absorber with large trapezoidal cavities was investigated by Reynolds [13]. In the simulation, the top surface of the cavity was set at 
$300^{\circ} \mathrm{C}$ and radiative and convective heat transfer was modeled in the absorber cavity. The simulation over-predicted experimental performance by $14 \%$.

Iordanou developed a simplified CFD model to investigate the use of a porous mesh in the fluid channel and found a 10\% enhancement in performance [7].

Marroquin carried out a CFD simulation of a full-size collector and compared the Reynolds number within rectangular and cylindrical pipework under the same flow conditions [11]. The study found that rectangular pipes had the greater Reynolds number but there were concerns about the difficulty of their construction.

Dovic developed a parametric CFD model to simulate the performance of a single fin segment of corrugated plate solar collectors [3]. In these collectors, the fluid is passed through the plate of the collector instead of through the pipework of a conventional collector. Dovic compared the findings to collectors that had tubes connected and found that the designs without tubes achieved a 7\% improvement to those with tubes under the same conditions.

Martinopoulos used CFD to simulate the performance of a polymer solar collector [12] and found good agreement between the simulated and experimental results. The collector used a black fluid and a single inlet pipe delivered flow to many rectangular riser channels. The study revealed a lot of variation in between the risers, with stagnant flow and high temperatures occurring in the center of the collector.

Manjunath and Karanth applied CFD models based on conjugate heat transfer and discrete transfer radiation model (DTRM) to investigate the use of fins inside the tube on thermal performance [10][9]. They concluded that serrations enhance the heat transfer between plate and the absorber due to increased surface area.

CFD has also been used externally to determine the average heat transfer coefficients for forced convection over a flat plate collector [17]. The study investigated the influence angle of attack on heat transfer in the tubes and it was concluded it was not greatly affected by the range of angles investigated. A summary of previous CFD studies is provided in Table 1. 
Table 1: Summary of previous CFD studies

Study Summary $\quad$ Reference

\begin{tabular}{|c|c|c|}
\hline Fan & $\begin{array}{l}\text { Collector pipes only }- \text { no } \\
\text { absorber. Heat flux } \\
\text { applied through pipe } \\
\text { walls. }\end{array}$ & [6] \\
\hline Selmi & $\begin{array}{l}\text { Single Pipe CFD with } \\
\text { radiative and convective } \\
\text { heat transfer. Heat loss did } \\
\text { not increase at higher } \\
\text { temperatures. }\end{array}$ & [14] \\
\hline Reynolds & $\begin{array}{l}\text { Simulation of single large } \\
\text { trapezoidal cavity. } \\
\text { Convective and radiative } \\
\text { heat transfer. }\end{array}$ & [13] \\
\hline Iordanou & $\begin{array}{l}\text { Single pipe investigation } \\
\text { of mesh inside collector } \\
\text { tubes }\end{array}$ & [7] \\
\hline Marroquin & $\begin{array}{l}\text { Rectangular and } \\
\text { cylindrical pipe network - } \\
\text { no absorber. }\end{array}$ & [11] \\
\hline Dovic & $\begin{array}{l}\text { Corrugated absorber } \\
\text { where flow ran either } \\
\text { through the plate or } \\
\text { connected pipe work. }\end{array}$ & [3] \\
\hline Martinopolous & $\begin{array}{l}\text { Flat polymer collector } \\
\text { with absorbent ink } \\
\text { suspended in water as the } \\
\text { heat removal fluid. } \\
\text { Numerous rectangular } \\
\text { risers. }\end{array}$ & [12] \\
\hline Manjunath & $\begin{array}{l}\text { Single pipe connected to } \\
\text { an absorber. }\end{array}$ & {$[10]$} \\
\hline
\end{tabular}

\section{Experimental Work}

Collector

A Serpentine and Header Riser absorber was constructed using Sunstrip Lazerplate fins (S-Solar, Sweden) which consisted of copper pipes laser welded to an aluminium sheet. Each absorber had the same dimensions $(510 \times 785 \mathrm{~mm})$ with 4 riser pipes running the length. 


\section{Thermal Efficiency Curves}

The thermal performance testing of the solar collector is performed following the methodology provided in earlier work [1]. The solar simulator consists of four 1000W metal halide lamps inside a parabolic reflector (Micro-Sun Reflective 90, Alanod Solar, Germany). The collector is mounted onto the frame and connected to a closed loop system, filled with deionized water. Temperature control is achieved using a second circuit containing a Presto A40 dynamic temperature control system (Julabo GmbH, Germany). An external Pt100 sensor is positioned at the collector inlet and connected to the control system to enable precision temperature control of the inlet temperature. A mass flow rate of $0.009 \mathrm{~kg} / \mathrm{s}$, is achieved using a Bronkhorst Cori-Flow M15 mass flow controller (Bronkhorst Cori-Tech B.V., The Netherlands) which controls the speed of a Tuthill, DGS series, gear pump (Tuthill, USA). Temperature monitoring is performed using Type-T thermocouples (Omega Engineering Limited, UK) positioned at the inlet and outlet of the collector.

Thermal efficiency curves were created for each collector by taking readings at steady state at 5 inlet temperatures $\left(21^{\circ} \mathrm{C}, 35^{\circ} \mathrm{C}, 50^{\circ} \mathrm{C}, 65^{\circ} \mathrm{C}\right.$ and $\left.80^{\circ} \mathrm{C}\right)$ following the guidelines of EN 12975-2. The values of $F_{R}$ and $U_{L}$ will be calculated from the results.

\section{Collector Temperature}

To measure the temperature distribution across the absorber, T-type thermocouples were fixed to the back of each fin using copper tape and positioned in the center. An evenly spaced grid of 32 thermocouples consisting of 8 columns and 4 rows was used. The measurements from the thermocouples were logged using Pico logger TC-08 (Picotech, UK) and readings were taken when the collector was in steady state.

\section{Numerical Work}

Geometry Creation and Meshing 
An IGES model of the collector was created where the length and width of the model matched that of the experimental collector; however, the thickness of the absorber plate was increased from $0.5 \mathrm{~mm}$ to $8 \mathrm{~mm}$ to ensure enough space for meshing; as the simulation is performed under steady state conditions, the capacitive effects of the thicker plate are not a contributing factor.

The diameter of the pipes connected to the back of the absorber is $8 \mathrm{~mm}$. The simulation assumes $D_{e}=D_{i}$. In the simulations, thermal contact was achieved through recession of the tubes into the plate. A contact length of $8 \mathrm{~mm}$ was assumed. The reference conductivity of aluminum from the CFX material library was used $\left(237 \mathrm{~W} / \mathrm{m}^{\circ} \mathrm{C}\right.$ at $\left.25^{\circ} \mathrm{C}\right)$.

A multi-domain mesh was created in ICEM 13.0. A 3-layer prism mesh was extruded at the heat transfer boundaries. The mesh was smoothed and the worst quality element was 0.2. A cross section of the mesh is shown in Figure 1.

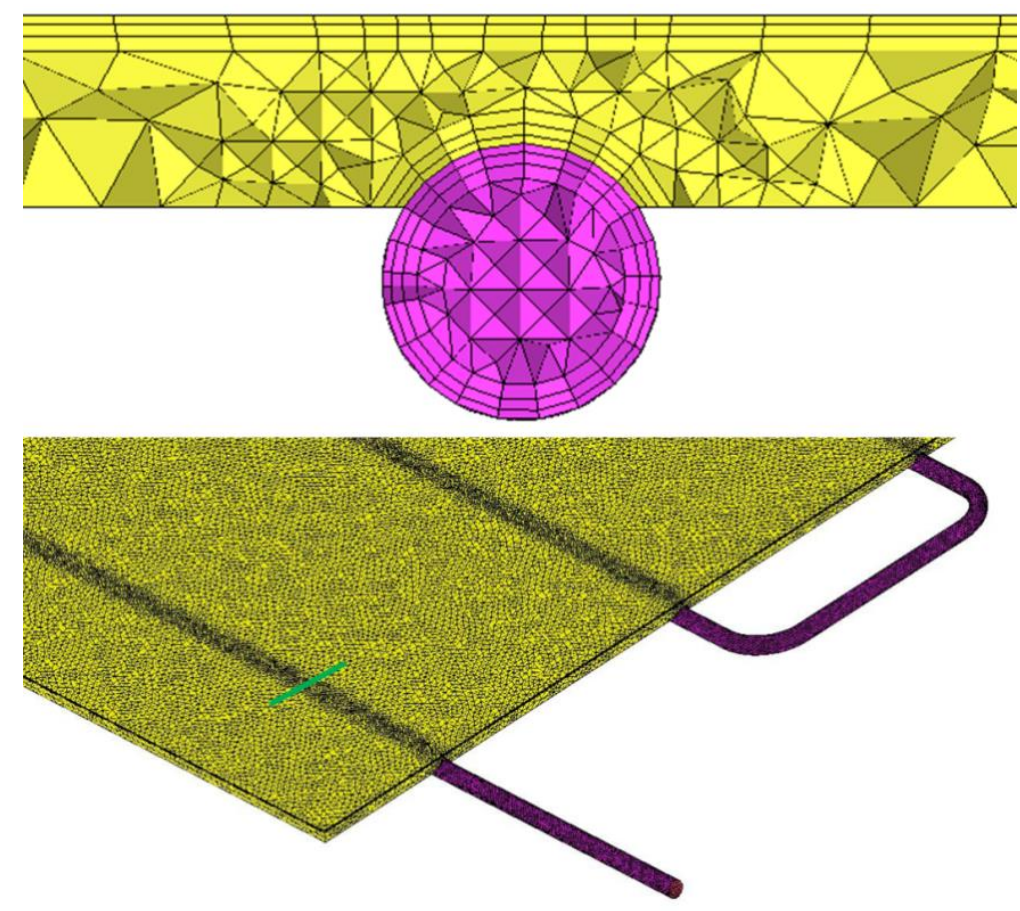

Figure 1: Mesh cross section through the pipe of the serpentine model

\section{Boundary Conditions}


The Reynolds number was calculated at 598 and 1795 for the Header Riser and Serpentine collector respectively; therefore, a laminar flow model was used in the simulations. There was sufficient distance in the experiment between the pump and inlet, $(>90 \mathrm{~cm})$ for fully developed laminar flow to form. To account for this condition in the CFD model, a user expression was applied to the inlet boundary to generate a velocity profile representative of fully developed flow laminar, see (4) [2].

$$
\begin{aligned}
& u_{r}=2 u_{\text {ave }}\left(1-\frac{r^{2}}{R_{\max }^{2}}\right) \\
& r=\sqrt{\left(i-i_{o}\right)^{2}+\left(j-j_{o}\right)^{2}}
\end{aligned}
$$

Where $R_{\max }$ is the radius of the pipe, $u_{\max }$ is the velocity at the center of the pipe, $r$ is the distance from the center, and $i$ and $j$ are coordinates $(\mathrm{x}, \mathrm{y}, \mathrm{z})$ when the inlet is positioned on the plane $i j$. The subscript o denotes the central coordinate of the inlet.

The top surface of the absorber was specified as a wall. The value of irradiance measured from the experiment was entered as the boundary energy source. The overall heat loss coefficient, determined from the experimental thermal efficiency curve, was also assigned to this boundary. The experimental ambient temperature is also assigned and this is used to drive the losses from the absorber surface. The expression used to determine losses is shown in (5).

$$
q_{\text {loss }}=U_{L}\left(T_{b}-T_{a}\right)
$$

Where $U_{L}$ is the measured heat loss coefficient, $T_{b}$ is the temperature at the boundary, as calculated by the solver, and $T_{a}$ is the measured ambient temperature. To achieve a mass flow rate of $0.009 \mathrm{~kg} / \mathrm{s}$ the appropriate velocity of fluid was specified at the inlet. The temperature dependence of density was compensated for. The outlet was specified with an average static pressure of 0 pa. 
Table 2 CFD Simulation Parameters

$\underline{\text { Parameter }} \quad \underline{\text { Value }}$

$\begin{array}{ll}\text { Mass and momentum } & \text { No slip wall }\end{array}$

Wall roughness $\quad$ Smooth

Buoyancy model $\quad$ Non-buoyant

$\underline{\text { Heat transfer model }} \quad$ Thermal energy

Turbulence model Laminar

Outlet Mass and Momentum $\quad$ Average static pressure. Relative pressure $0 \mathrm{~Pa}$

Fluid Model Water - Ansys material properties library

Plate Boundary $\quad$ Radiation source with CEL expression 1000 toplosscoeff*(T - Tamb)

Inlet Static Temperature $\quad 21^{\circ} \mathrm{C}, 35^{\circ} \mathrm{C}, 50^{\circ} \mathrm{C}, 65^{\circ} \mathrm{C}$ and $80^{\circ} \mathrm{C}$

\begin{tabular}{|c|c|}
\hline $\begin{array}{l}\text { Inlet Mass and Momentum - } \\
\text { Normal Sneed }\end{array}$ & Serpentine $8 \mathrm{~mm}$ pipe $=0.1794 \mathrm{~m} \mathrm{~s}^{\wedge}-1$ \\
\hline & Header Riser $12 \mathrm{~mm}$ pipe $=0.05103 \mathrm{~m} \mathrm{~s}^{\wedge}-1$ \\
\hline & Mass flow rate the same in both collectors \\
\hline Toplosscoeff & $\begin{array}{l}\text { From experimental thermal efficiency curve. } \\
\text { Serpentine }=11.84 \mathrm{~W} / \mathrm{m}^{2 \circ} \mathrm{C} \text { Header Riser }= \\
11.84 \mathrm{~W} / \mathrm{m}^{2 \circ} \mathrm{C}\end{array}$ \\
\hline Ambient Temperature Tamb & $21^{\circ} \mathrm{C}$ \\
\hline
\end{tabular}




\section{Solver}

A definition file was created for the boundary conditions and then processed by CFX Solver Version 13.0. Convergences of the following residuals were monitored; momentum, mass, heat transfer and energy balance and the simulation was run for a minimum of 600 iterations. In all cases the residuals reached less than $10^{-5}$ and an energy imbalance of zero. The time taken for the simulation ranged from 1.5 hour to 3 hours. Individual simulations were carried out for each inlet temperature; $21^{\circ} \mathrm{C}, 35^{\circ} \mathrm{C}, 50^{\circ} \mathrm{C}$, $65^{\circ} \mathrm{C}$ and $80^{\circ} \mathrm{C}$. The ambient temperature for all simulations was set at $21^{\circ} \mathrm{C}$.

\section{Mesh Sensitivity}

A mesh sensitivity study was carried out by refining the mesh size in areas of interest. Reducing the size of the mesh increases the number of the cells in the domain. By reducing the size of the cells on the pipe-absorber interface from $2 \mathrm{~mm}$ to $1.0 \mathrm{~mm}$ saw a $140 \%$ increase in the number of cells in the domain. This increased computation time from 1.5 hour to 5 hours and there was a $5 \%$ difference in the results. A $1.5 \mathrm{~mm}$ size control was a good compromise between speed and accuracy, computation time was 3 hours and there was $0.8 \%$ difference relative to the $1 \mathrm{~mm}$ mesh.

\section{Flow Analysis}

The mass flow in a header riser collector is split between risers. To investigate the effect this has on the surface temperature of the absorber, different flow patterns in a header riser collector were simulated. The flow conditions were created by assigning different inlet and outlet configurations.

\section{Results}

Calculation of $U_{L}$ and $F_{R}$

Figure 2 and Table 3 compares the thermal characteristics calculated using the experimental and simulated results. In the case of the serpentine collector, the simulated efficiency differed from the experimental efficiency by around 3\% (abs.) across the 
temperature range. The heat removal factor and heat loss coefficient differed by around $4 \%$ (abs.).

The efficiency of the Header Riser collector had varying agreement between the experimental and simulated values across the temperature range. Ranging from $-7.5 \%$ (abs.) at zero loss efficiency to approximately $+4.5 \%$ (abs.) at the end of the temperature range tested. The values of $F_{R}$ and $U_{L}$ for the header riser collector varied by $12 \%$ and $7.9 \%$ respectively.

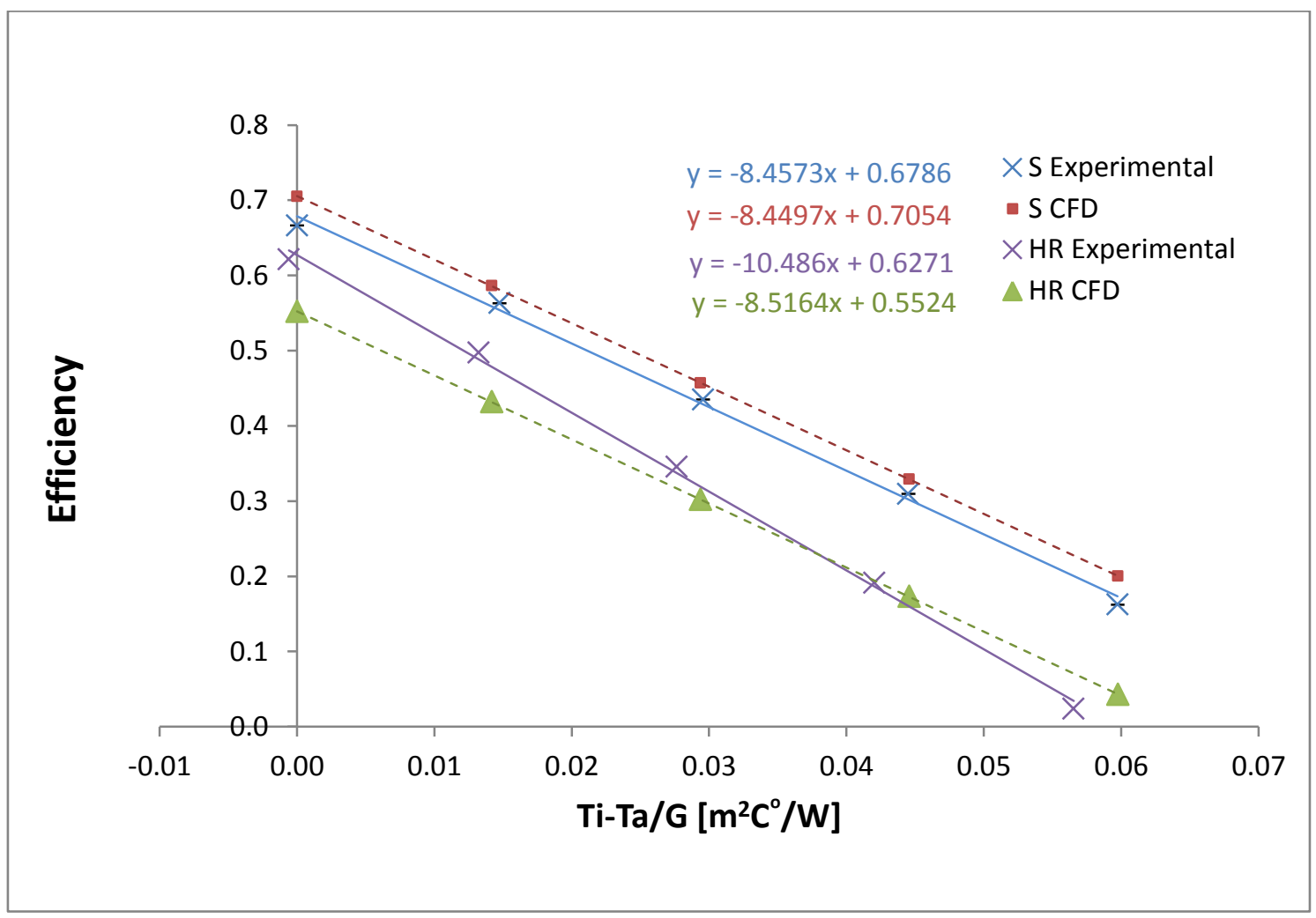

Figure 2: Thermal efficiency curve of the simulation vs experimental results 
Table 3: Comparison of the thermal performance characteristics from experiment and simulation

\begin{tabular}{|c|c|c|c|c|}
\hline \multirow[b]{2}{*}{ Parameter } & \multicolumn{2}{|c|}{ Experimental } & \multicolumn{2}{|c|}{ Simulation } \\
\hline & $\begin{array}{l}\text { Serpentine } \\
\text { (abs) }\end{array}$ & $\begin{array}{l}\text { Header Riser } \\
\text { (abs) }\end{array}$ & $\begin{array}{l}\text { Serpentine } \\
\text { (abs) }\end{array}$ & $\begin{array}{c}\text { Header } \\
\text { Riser } \\
\text { (abs) }\end{array}$ \\
\hline $\begin{array}{c}\text { Zero Loss Efficiency } \\
F_{R}(\alpha t)\end{array}$ & $67.86( \pm 2.19) \%$ & $62.71( \pm 2.08) \%$ & 70.54 & 0.5524 \\
\hline$U_{L} F_{R}\left[\mathrm{~W} / \mathrm{m}^{2 \circ} \mathrm{C}\right]$ & $8.4573 \pm 0.071$ & $10.486 \pm 0.08$ & 8.4497 & 8.5164 \\
\hline $\begin{array}{c}F_{R} \\
U_{L}\left[\mathrm{~W} / \mathrm{m}^{2 \circ} \mathrm{Cl}\right.\end{array}$ & $\begin{array}{l}0.71 \pm 0.037 \\
11.84 \pm 0.60\end{array}$ & $\begin{array}{l}0.66 \pm 0.035 \\
15.89 \pm 0.84\end{array}$ & $\begin{array}{c}0.74 \\
11.39\end{array}$ & $\begin{array}{c}0.58 \\
14.64\end{array}$ \\
\hline
\end{tabular}

\section{Calculation of $U_{L}$ using mean plate temperature}

As the value of $U_{L}$ and $F_{R}$ are linked in the relationship shown in (2), the discrepancy in the results could be a result of the simulation compensating one factor in place of the other. This arises because the simulation represents an ideal case whereas in the experimental case it is not possible to know the exact value of $F_{R}$. The causes of this are discussed later in this article but such differences could arise from the poor thermal contact between the plate and the tube in the experimental case. In the case of the header riser collector the effects are more pronounced and this could be a result of lower flow rates through the collector.

To investigate this further the average plate temperature can be determined from the results of the CFD simulation; therefore, $U_{L}$ can be calculated independently of $F_{R}$. This approach is shown in Figure 3. The value of $U_{L}$ calculated using this approach is $12.18 \mathrm{~W} / \mathrm{m}^{2 \circ} \mathrm{C}(+2.9 \%$ difference with experimental $)$ and $15.78 \mathrm{~W} / \mathrm{m}^{2 \circ} \mathrm{C}(+0.7 \%$ difference with experimental) for the serpentine and header riser collector respectively. This improvement between simulation and experimental results indicates that uncertainty in $F_{R}$ value causes discrepancies between the simulated and experimental case when plotting a conventional thermal efficiency curve. It is advised that the mean plate temperature approach is used to determine the heat loss coefficient. 


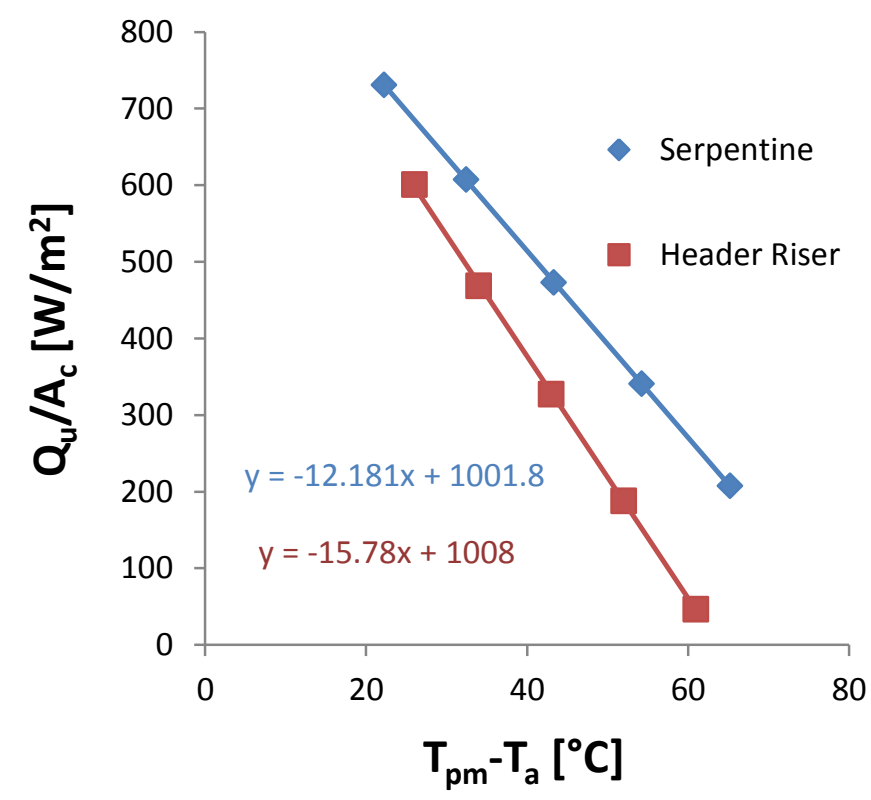

Figure 3: Calculation of $U_{L}$ independently of $F_{R}$

\section{Absorber Temperature}

In Table 4 a comparison has been made between the simulated values of average absorber temperature and those measured using the thermocouples attached to the back of the absorber. For the serpentine collector, the simulated absorber temperature was less than the experimental value at all data points. The difference varied from $1.17 \%$ at $50^{\circ} \mathrm{C}$ inlet temperature to $2.54 \%$ at the $21^{\circ} \mathrm{C}$ inlet temperature.

For the header-riser collector, the simulated value is over estimated by $4.87 \%$ at the first data point at inlet temperature of $21^{\circ} \mathrm{C}$ and then becomes increasingly underestimated until the last data point where the simulated value is $7.16 \%$ less than the experimental value. 
Table 4: Comparison of surface temperature distribution for the simulated and measured experimental values.

\begin{tabular}{cccccc}
\hline \multicolumn{3}{c}{ Header Riser } & \multicolumn{3}{c}{ Serpentine } \\
\hline $\begin{array}{c}\text { Experimental } \\
{\left[{ }^{\circ} \mathbf{C}\right]}\end{array}$ & $\begin{array}{c}\text { Simulated } \\
{\left[{ }^{\circ} \mathbf{C}\right]}\end{array}$ & $\begin{array}{c}\text { Difference } \\
{[\mathbf{\%}]}\end{array}$ & $\begin{array}{c}\text { Experimental } \\
{\left[{ }^{\circ} \mathbf{C}\right]}\end{array}$ & $\begin{array}{c}\text { Simulated } \\
{\left[{ }^{\circ} \mathbf{C}\right]}\end{array}$ & $\begin{array}{c}\text { Difference } \\
{[\%]}\end{array}$ \\
\hline 44.4 & 43.2 & $2.5 \%$ & 44.9 & 47.1 & -4.9 \\
54.5 & 53.4 & $1.9 \%$ & 55.6 & 55.4 & 0.4 \\
65.10 & 64.3 & $1.2 \%$ & 66.5 & 64.3 & 3.4 \\
76.5 & 75.3 & $1.6 \%$ & 77.4 & 73.1 & 5.6 \\
87.7 & 86.2 & $1.7 \%$ & 88.3 & 82.0 & 7.2 \\
\hline
\end{tabular}

The distribution of the temperature is compared in Figure 4 and Figure 5 for the serpentine and header riser collector respectively.

Temperature

Surface Temperature
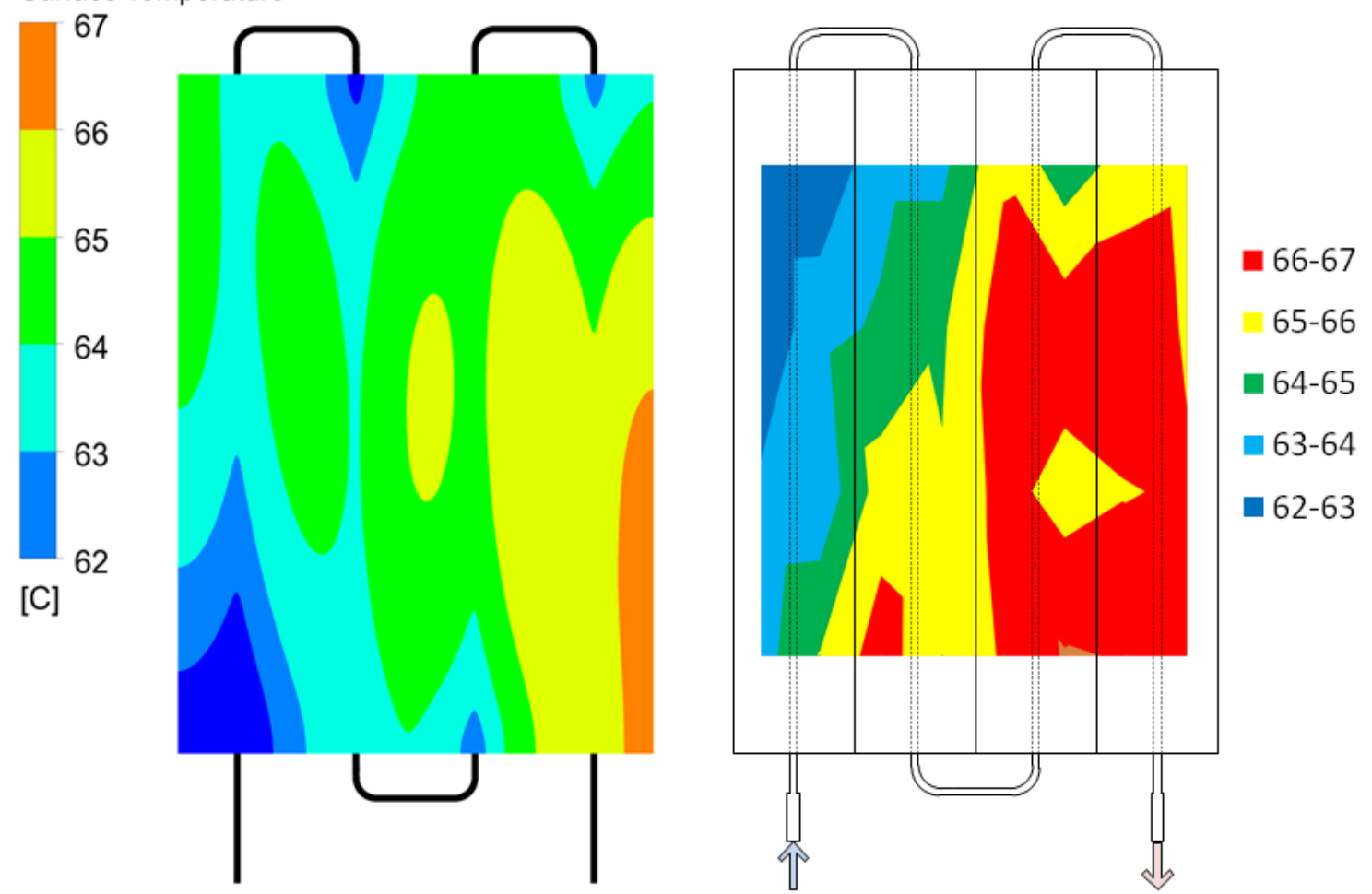

Figure 4: Comparison of the serpentine surface temperature distribution for the simulation (left) and from the experimental thermocouples (right) 


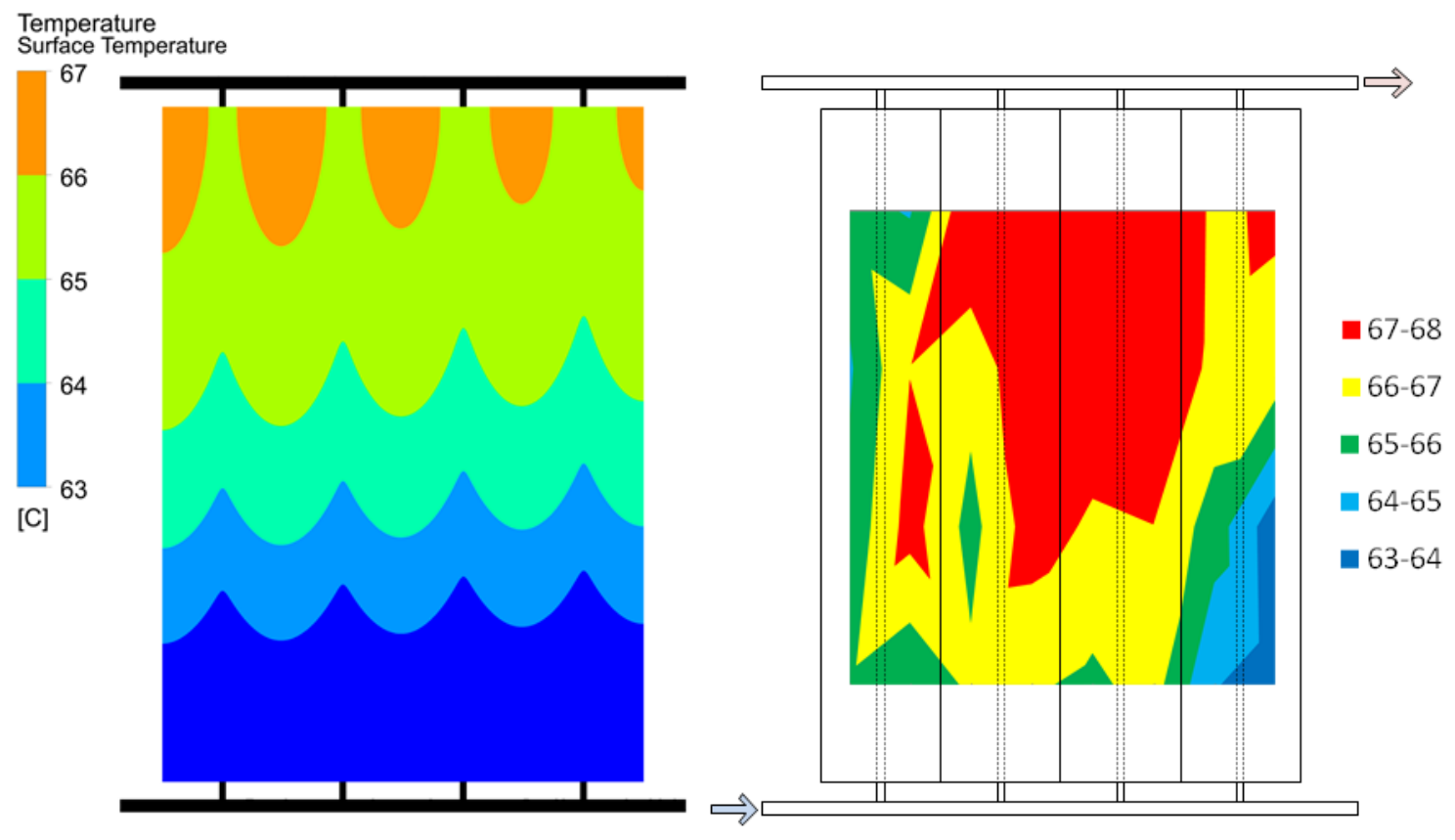

Figure 5: Comparison of the header rider surface temperature distribution for the simulation (left) and from the experimental thermocouples (right)

In the serpentine collector, there is a variation in temperature across the width of the collector in both the simulated and the experimental results. In the simulation results of the serpentine design, cold areas occur on the collector surface after each bend. This is a result of increased heat transfer due to fluid mixing as it moves around the bend. In the header riser collector, there is a temperature gradient along the y-axis; this differs to the results of the serpentine collector, where a temperature gradient is seen along the $\mathrm{x}$-axis. 
The results for the flow study are shown in Figure 6 and Figure 7. The most efficient systems were the single $\mathrm{Z}$ and $\mathrm{U}$ flow designs. The best performing dual flow design was the X-flow and the opposite and parallel flow collectors were the worst performers with thermal efficiencies of 0.236 and 0.002 respectively.

There is variation in the distribution of temperature for each design and this influences the efficiency of the collector. The flow distributions simulated in these individual collectors agree with the results of previous studies [19][8]. In this study the collector only consisted of four risers, this is a relatively small number for a thermal collector. It has been shown that as the number of risers increases, the flow becomes less uniform in the central pipes [8]. The most uniform distribution through the pipe was achieved using the X-flow configuration. In this case two inlets and outlets were used. The reason this design had the highest uniformity is because the parallel component consisted of only 2 risers. The reason this configuration is not as efficient as the single flow conditions is due to a slightly higher average surface temperature. This could be a result of a loss in fluid momentum as the two flows collide. The lowest performing collectors were the ones with opposite and parallel flow. These cases represent an infinitely long parallel connection. This effect was also seen in the study by Wang [18] where the flow distribution was measured in a parallel connected array consisting of 16 collectors, each with 10 risers. The study showed that most of the flow travelled through the first and last risers of the collector. These findings indicate that even if the temperature distribution is relatively small across a single collector, care must be taken when connecting collectors in an array as the effect will be multiplied. 

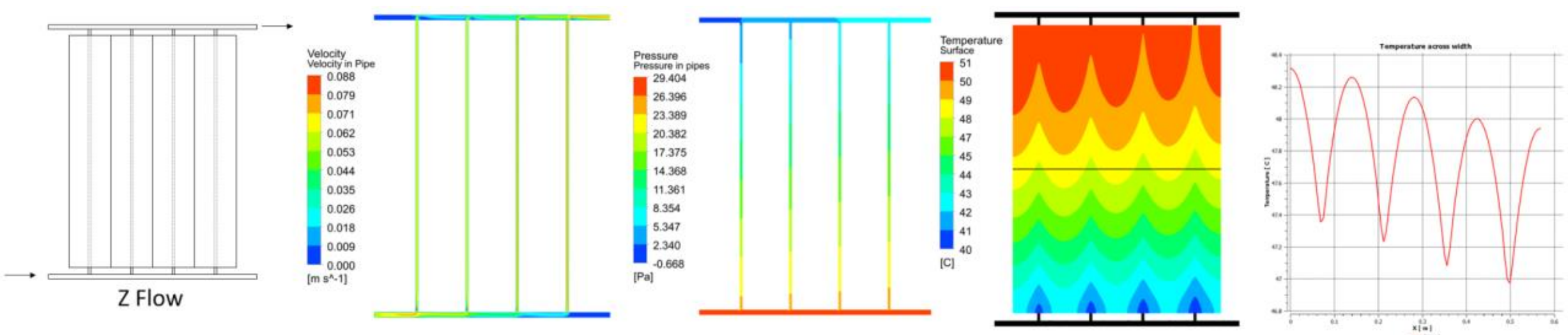

$\eta_{t}=0.553$
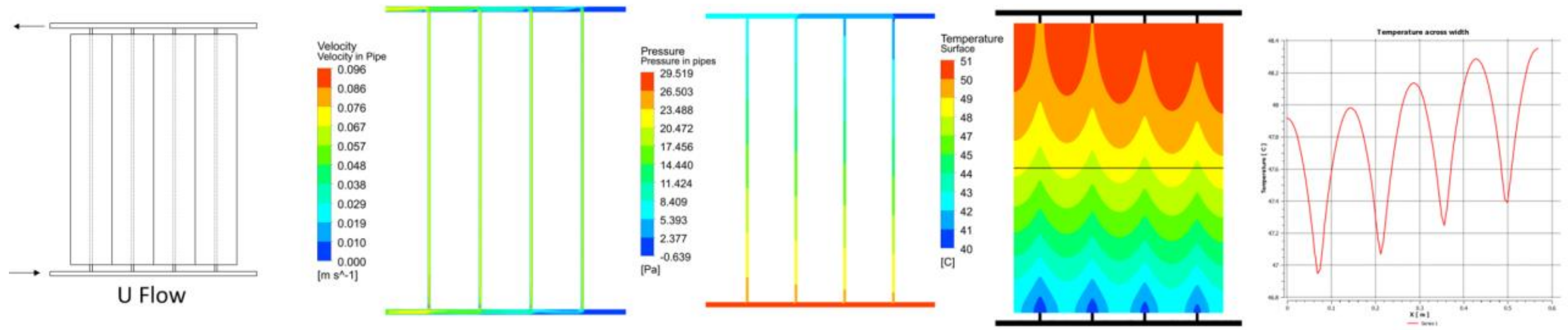

$\eta_{\mathrm{t}}=0.553$

Figure 6: Comparison of single flow conditions for a parallel collector. Inlet temperature at $21^{\circ} \mathrm{C}$ 

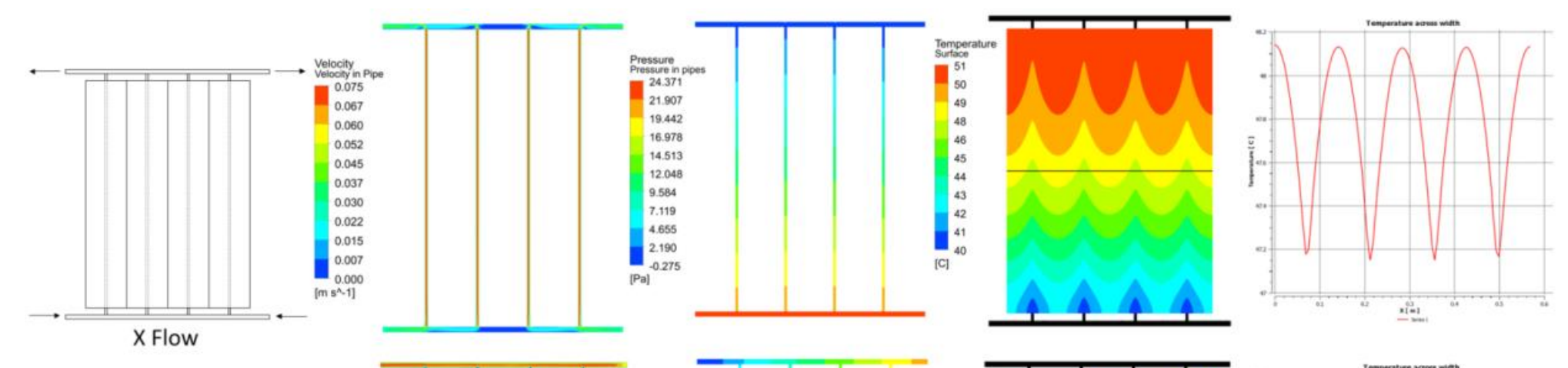

$\eta_{t}=0.548$
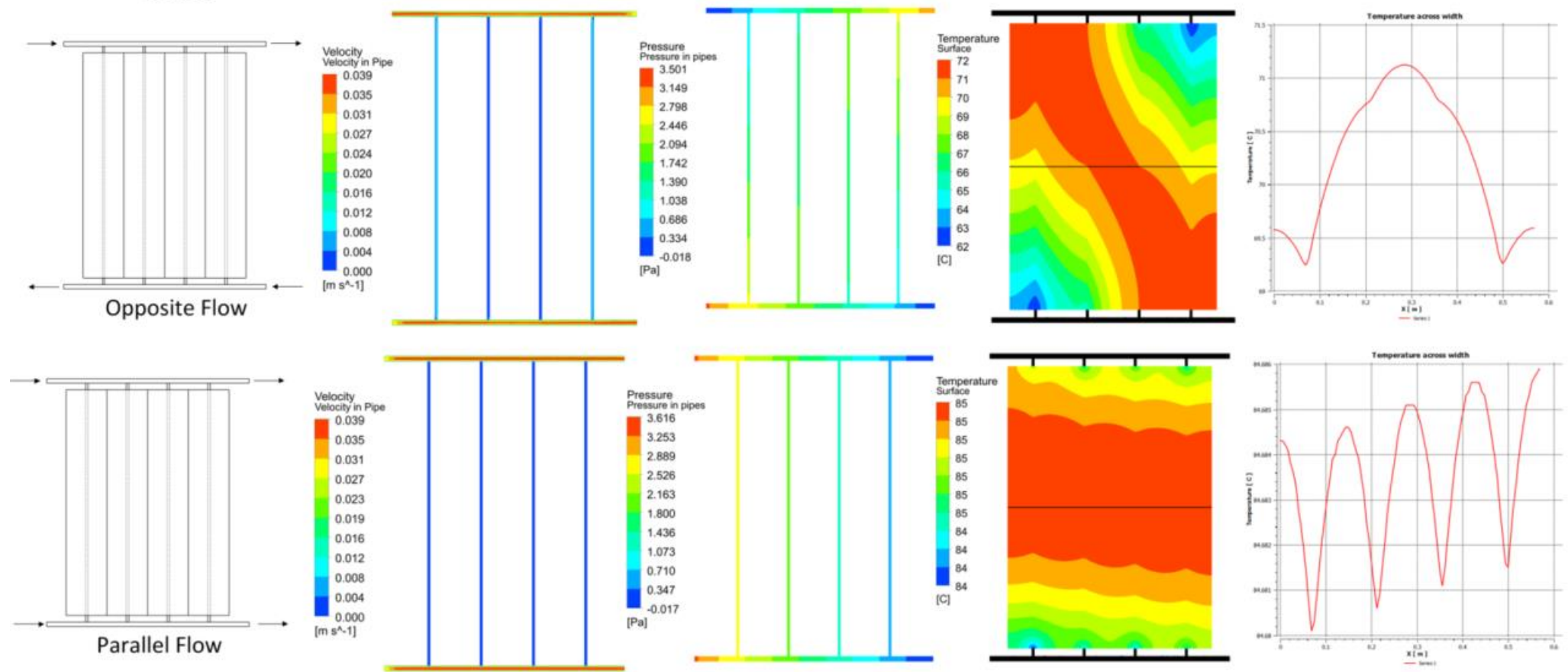

$\eta_{\mathrm{t}}=0.002$

Figure 7: Comparison of dual flow systems. Inlet temperature at $21^{\circ} \mathrm{C}$ 


\section{Discussion}

In this study the simulation represents an ideal case with perfect connection between the pipes and the absorber; however, when the results were compared against experimental case, there were some discrepancies.

The first issue was caused using a thicker plate to allow for meshing. A thicker plate increases the heat removal factor of the collector because more heat is can be absorbed by the tubes [5]. To compensate the thermal conductivity of the plate should be reduced in proportion to the increase in thickness. An analysis with the Hottel Whillier Bliss model shows that an increase from $0.5 \mathrm{~mm}$ to $8 \mathrm{~mm}$ results in a $12 \%$ increase in efficiency. This could explain the case for the serpentine collector but for the header riser collector, a decrease in efficiency is seen in the CFD model. As overall heat loss, $U_{L}$ is dependent on heat removal factor $F_{R}$, see (6), a thicker collector should have a lower heat loss coefficient under the same conditions.

$$
F_{R}=\frac{Q_{u}}{A_{c}\left[\left(S-U_{L}\left(T_{i}-T_{a}\right)\right)\right]}
$$

In the CFD model an increase in thickness should increase the energy output; however, to satisfy the specified heat removal factor from the experimental measurement, the value of $F_{R}$ is reduced to maintain energy balance.

This however contradicts the results from the serpentine collector, where the simulation outperforms the experimental measurement. The difference in experimental and simulated results from the serpentine collector could be explained by the influence of poor resistance on efficiency, resistance values were assigned to the pipe absorber boundary during boundary definition. The impact of increasing the contact resistance between the tube and the plate thermal efficiency is shown in Table 5. 
Table 5: Influence of increasing the thermal contact resistance between the absorber and the pipe on efficiency of serpentine collector

\begin{tabular}{cc}
\hline Resistance $\left[\mathbf{m}^{2 \circ} \mathbf{C} / \mathbf{W}\right]$ & Thermal Efficiency \\
\hline 0 & 0.729 \\
0.00025 & 0.693 \\
0.0005 & 0.667 \\
0.001 & 0.629 \\
\hline
\end{tabular}

It can be seen from Table 2, that the simulation could be adjusted to account for poor thermal contact; however, thermal contact is unreliable and unquantifiable in the laser welded thermal collectors used in this experiment, see Figure 8. The integrity of the bond between the pipe and the absorber is uncertain and without an accurate measurement of the conductivity across this boundary, discrepancy could occur between the experimental and simulated values.

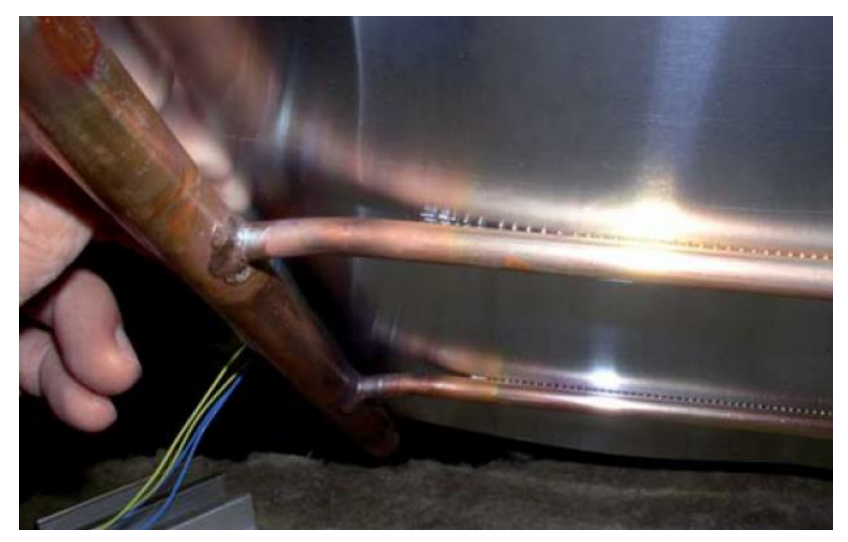

Figure 8: Separation of laser welded pipes on similar absorber [15]

The heat transfer surface area can also influence the efficiency of the collector. Three models were created with varying contact length between the pipe and the absorber. It was found that, if the contact length was increased to $12 \mathrm{~mm}$, the thermal efficiency increased to 0.82 and if the contact length was reduced to $4 \mathrm{~mm}$ the thermal efficiency reduced to 0.68 . 


\section{Conclusion}

Thermal efficiency curves are the de-facto experimental method to assess the performance of a solar collector and this is the first CFD methodology that has been used to simulate a thermal efficiency curve of a solar collector. This will enable engineers and designers to understand the performance of the collector before submitting it for testing. The methodology can also be applied to novel designs of solar collector to optimize performance avoiding the expense of experimental prototyping. The work detailed in this study goes beyond previous work by incorporating a loss coefficient and validating across a range of inlet temperatures.

The source of discrepancy between the simulated, ideal case and the experimental, non-ideal case has been identified as poor thermal contact between the pipes and the absorber. It was not possible to quantify this in the collectors used in this study however the simulation proved useful as a relative comparison between designs rather than giving quantitative results about performance. If a more quantitative analysis is required, then care must be taken in the manufacturer of the collectors to be simulated so that the exact thermal contact between the plate and the tubes is known and entered as a parameter within the simulation set-up. The cost and complexity of achieving this must be balanced against the benefits achieved by replicating exact thermal efficiency curves using CFD. The approach detailed in this study is deemed to be more suited to relative comparisons of designs as demonstrated in the flow comparison study. This will allow a designer to compare the relative improvement in efficiency and average surface temperature for any number of designs before building an experimental prototype.

\section{Acknowledgements}

This work was sponsored by ChapmanBDSP and the Engineering and Physical Research Council, UK.

\section{References}

[1] James Allan, Zahir Dehouche, Sinisa Stankovic, and Lascelle Mauricette.

Performance testing of thermal and photovoltaic thermal solar collectors. Energy Science \& Engineering, 3(4):310-326, 2015. 
[2] YA Cengel. Heat Transfer a Practical Approach. McGraw-Hill, 1998.

[3] Damir Dovic and Mladen Andrassy. Numerically assisted analysis of flat and corrugated plate solar collectors thermal performances. Solar energy, 86(9):2416-2431, 2012.

[4] J. Duffie and W. Beckman. Solar engineering of thermal processes, 1991.

[5] John A Duffie and William A Beckman. Solar engineering of thermal processes. John Wiley \& Sons, 4th edition, 2013.

[6] Jianhua Fan, Louise Jivan Shah, and Simon Furbo. Flow distribution in a solar collector panel with horizontally inclined absorber strips. Solar energy, 81(12):1501-1511, 2007.

[7] G. Iordanou. Flat-Plate Solar Collectors for Water Heating with Improved Heat Transfer for Application in Climatic Conditions of the Mediterranean Region. $\mathrm{PhD}$ thesis, Durham University, 2009.

[8] GF Jones and Noam Lior. Flow distribution in manifolded solar collectors with negligible buoyancy effects. Solar energy, 52(3):289-300, 1994.

[9] K Vasudeva Karanth, MS Manjunath, and N Yagnesh Sharma. Numerical simulation of a solar flat plate collector using discrete transfer radiation model (dtrm)-a cfd approach. In Proceedings of the World Congress on Engineering, volume 3, pages 6-8, 2011.

[10] M.S. Manjunath, K. Karanth Vasudeva, and Yagnesh N. Sharma. Three dimensional numerical analysis of conjugate heat transfer for enhancement of thermal performance using finned tubes in an economical unglazed solar flat plate collector. In Proceedings of the World Congress on Engineering 2011, 2011.

[11] JA Marroquin, J.M. Manuel, Olivares-Ramrez, J.S. Omar, M. Antonio, ZamoraAntuñano, and A. Encinas-Oropesa. Analysis of flow and heat transfer in a flat solar collector with rectangular and cylindrical geometry using cfd. IngenieráInvestigación y Tecnologá, 14(4):553-561, 2013. 
[12] G Martinopoulos, D Missirlis, G Tsilingiridis, K Yakinthos, and N Kyriakis. Cfd modeling of a polymer solar collector. Renewable Energy, 35(7):1499-1508, 2010.

[13] DJ Reynolds, MJ Jance, M Behnia, and GL Morrison. An experimental and computational study of the heat loss characteristics of a trapezoidal cavity absorber. Solar Energy, 76(1):229-234, 2004.

[14] Mohamed Selmi, Mohammed J Al-Khawaja, and Abdulhamid Marafia. Validation of cfd simulation for flat plate solar energy collector. Renewable energy, 33(3):383-387, 2008.

[15] Alanod Solar. Microtherm absorber fact book. 2012.

[16] Luca A Tagliafico, Federico Scarpa, and Mattia De Rosa. Dynamic thermal models and cfd analysis for flat-plate thermal solar collectors - a review. Renewable and Sustainable Energy Reviews, 30:526-537, 2014.

[17] Oguz Turgut and Nevzat Onur. Three dimensional numerical and experimental study of forced convection heat transfer on solar collector surface. International Communications in Heat and Mass Transfer, 36(3):274-279, 2009.

[18] XA Wang and LG Wu. Analysis and performance of flat-plate solar collector arrays. Solar Energy, 45(2):71-78, 1990.

[19] Volker Weitbrecht, David Lehmann, and Andreas Richter. Flow distribution in solar collectors with laminar flow conditions. Solar Energy, 73(6):433-441, 2002. 